\title{
Academic Library Approval Plans: A Nationwide Inquiry
}

\author{
John H. Reidelbach \\ Chairperson, Collection Development \\ University Library \\ University of Nebraska at Omaha \\ Gary M. Shirk \\ Head of Acquisitions \\ Wilson Library \\ University of Minnesota
}

To date professional inquiry concerning approval plan vendors has centered almost exclusively on the concepts and mechanics of their operation. In 1980, Paul H. Mosher wrote that "we (librarians) talk about rating vendors and evaluating their services, but we seldom ever get around to doing so." Mosher's comments are still valid today, as borne out by an extensive manual and computerized examination of both United States and British library literature since 1960. Literature searches also reveal that scholarly investigation of approval plan vendors tend to be either local or regional in nature and limited in the number of vendors studied.

To remedy these deficiencies in the literature of research regarding approval plans, the authors have embarked on a three-phase program of research. The first phase of research has culminated in a recently published article titled, "Selecting an Approval Plan Vendor: A Step-by-Step Process." A second phase of research currently underway involves summarizing extensive data previously obtained from eight approval vendors regarding various aspects of their operations and services. A third phase of research commenced in late June. A fiftythree item questionnaire was mailed to approximately 640 academic libraries to request user librarian evaluation of domestic approval vendor services.

The authors had previously reported that eight approval plan vendors would be actively involved in nationwide distribution of the approval plan evaluation questionnaire. ${ }^{3}$ While extremely grate-

\footnotetext{
${ }^{1}$ Paul H. Mosher, "Waiting for Godot: Rating Approval Service Vendors," in Shaping Library Collections for the 1980s, ed. Peter Spyers-Duran and Tomas Mann, Jr. (Phoenix: Oryx Press, 1980), 159-66.

${ }^{2}$ John H. Reidelbach and Gary M. Shirk, "Selecting an Approval Plan Vendor: A Step-by-Step Process," Library Acquisitions: Practice and Theory $7(1983): 115-122$.

John H. Reidelbach and Gary M. Shirk, "Research in Progress," Library Acquisitions: Practice and Theory 7(1983):123-125.
}

ful for the cooperation expressed by the vendors, the authors were cognizant of the implications and disadvantages of vendor assistance with distribution of the questionnaire. Therefore, a grant was applied for from the University Committee on Research at the University of Nebraska at Omaha. In late May, a grant of $\$ 1,400$ was awarded from the University Committee on Research partially to cover expenses associated with mailing and followup of the nationwide approval evaluation questionnaire. Additional costs involved in distribution and follow-up of the study are being supported by the University Library at the University of Nebraska at Omaha. The questionnaire was initially mailed to acquisitions librarians at all college and university libraries in the United States with book budgets of $\$ 50,000$ or more. Project director John Reidelbach and co-investigator Gary Shirk now seek responses from all college and university libraries currently dealing with one or more domestic approval plan vendors, regardless of book budget.

The research emanating from this survey will be of interest to library directors, acquisitions, collection development, and reference professionals. Formal and informal discussions at conferences indicate that these individuals continually seek hard data regarding the efficiency of their own and other approval plan dealers. The approval plan vendors themselves will benefit from the availability, for the first time, of a massive body of empirical data regarding librarian satisfaction or dissatisfaction with their own company as well as that of their competitors. Perhaps vendors will use this data to build on their individual strengths and to take whatever measures may be necessary to correct any weaknesses or shortcomings identified by the questionnaire results.

In September 1982, a forty-question test version of the nationwide questionnaire was sent to thirty-one libraries in the eight-state Mountain Plains Library Association (MPLA) region. This test was conducted with two objectives in mind:

a. To ascertain the degree of interest on the part of acquisitions and collection development librarians concerning this particular aspect of library research;

b. To identify and correct omissions or unclear statements before preparation of the final questionnaire.

Both objectives were successfully met. Response was exceptional: a $96.7 \%$ rate of return was achieved. Because of the overwhelming rate of return in the regional study, the investigators believe interest in the nationwide inquiry will be similarly 


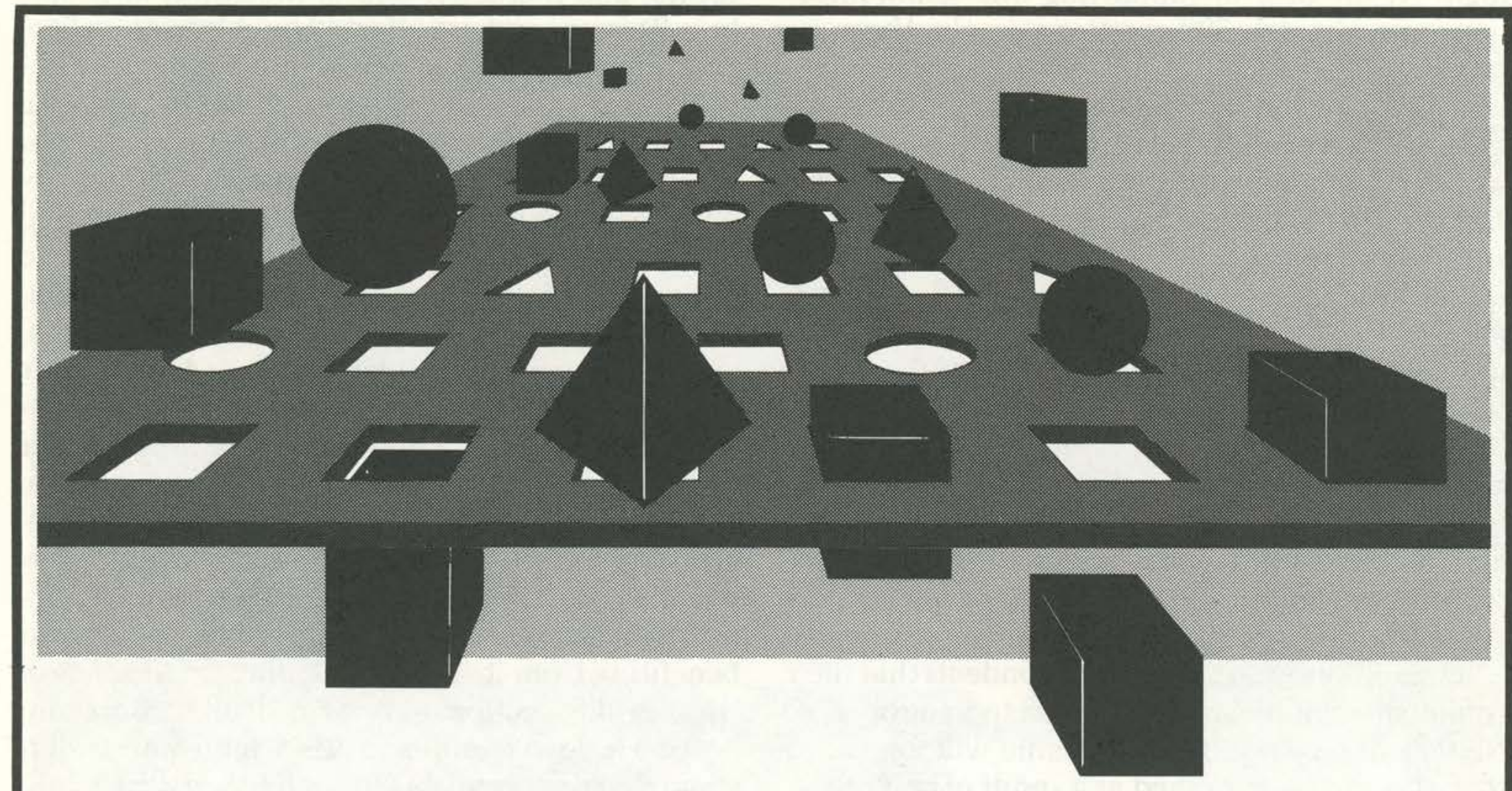

TO GET THE BEST FITTING APPROVAL PROGRAM...

\section{START WITH THE LARGEST SELECTION}

The diverse disciplinary demands of collection development require the Approval Program with the most comprehensive title coverage. Each year, our Approval Program identifies over 35,000 titles-10,000 more than any other program. Notification slip orders retain full service privileges and our discounts are the best available. Automatic management reports are issued regularly, and no program service charges are ever added.

For details, contact the Sales Department of the division nearest you. 
high. At the time of submitting this communication approximately 300 questionnaires had been returned.

If you have an active domestic approval plan, did not receive a questionnaire, and wish to participate in this nationwide research effort, please contact John Reidelbach, Chairperson, Collection Development, University Library, University of Nebraska at Omaha, Omaha, NE 68182, or phone (402) 554-2846. A copy of the questionnaire will be sent to you immediately. The questionnaire can be completed in approximately 30 minutes.

Position responsibilities in a given library may necessitate that more than one person provide the requested information. It would be most appreciated if the person initially receiving the questionnaire would pass it along to the appropriate person(s) for completion.

The authors wish to assure respondents that their comments will be held in the strictest confidence. Neither library nor librarian name will appear in the article to be published as a result of this study. Furthermore, none of the vendors will be provided access to the individual librarian responses.

Deadline for the return of questionnaires is October 31, 1983. Submission of the final manuscript to a professional journal is anticipated in June, 1984.

\section{Letter}

\section{Special Collections}

\section{To the Editor:}

There are two points concerning libraries' reactions to difficult economic times which I do not believe have been considered by many institutions. The comparison between the number of users of Special Collections with the number of users of the general library is, as every Special Collections librarian knows, a false standard. It is, however, the one that is frequently used by administrative directors in apportioning budgets. An alternative and more realistic analysis, or comparison, should be based upon the number of persons affected, or potentially affected, by the uses of Special Collections.

In listening to discussions of comparisons of the number of users in each area, I thought of a friend who writes historical novels. He is noted for creating a sense of living during the time period of his fiction, and he therefore does extensive research in Special Collections departments. He would be counted as one researcher, or possibly the number of days would be considered, to arrive at "researcher-days." The impact of the services provided to him by the Special Collections department is, however, far greater than any such statistic would indicate. His books sell tens of thousands of copies, and therefore, tens of thousands of people benefit from, and are affected by, his work in Special Collections departments.

We were able to demonstrate this effect several years ago in conjunction with an appraisal of a major archive. We surveyed the approximately 600 researchers who had used the collection since it had been available; approximately 400 responded to our survey. A large number were doing genealogical research, or other specific personal research, and there was no benefit beyond their own use. We did, however, demonstrate that a significant number of articles had been published based upon the collection. We were aware of several major books, but the number of other publications was a significant surprise. To simply state that during a fiveyear period, 600 people use this Collection is to understate dramatically the number of persons benefiting from it. The quality and importance of the uses of collections may be difficult to ascertain; however, few administrators would not understand that a use resulting in a published article cannot be equated with an individual checking general references in the general library.

The second point concerns fund raising. Friends of Libraries, and other knowledgeable groups involved with Special Collections, may frequently make large cash contributions which are not for specific purchases or projects. When other groups are approached, particularly the business community, it is important to relate the contribution to a specific expenditure or need. My involvement with libraries raising funds has repeatedly shown this to be true. Potential donors can relate to acquiring a specific collection (with a detailed explanation as to why the library wants it and how scholarship will benefit from its being available) or giving funds to process a collection after they have been shown the collection and had its importance explained.

Those who understand the activities of Special Collections will continue to make general cash contributions, but those who really do not understand the importance of Special Collections, but are potential donors, need to be told why the money is needed, what you will do with it, and what benefits people will receive from it. You will be offering to these potential donors, who do not already have the appreciation of the field, the opportunity to do something worthwhile with their money that they are able to relate to. This approach I have found has had quite significant results.-Kenneth Rendell, The Rendells, Inc., Newton, Massachusetts.

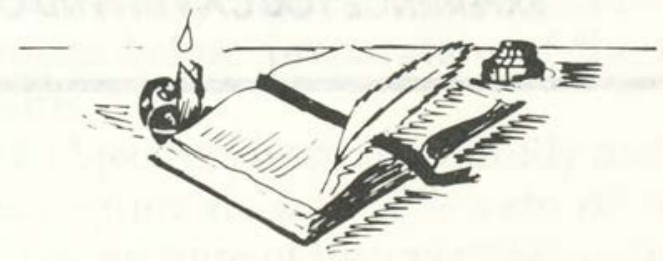

